\title{
DETERMINATION OF MANGANESE IN STEEL AND IRON BY THE PERSULPHATE-ARSENITE METHOD
}

\author{
By H. A. Bright and C. P. Larrabee
}

ABSTRACT

The advantage of using phosphoric acid in the persulphate-arsenite method and the effect of certain dissolved salts on the titration of permanganic acid by sodium arsenite are discussed. A description is given of the persulphatearsenite method as used at the Bureau of Standards. In the recommended procedure, which embodies no new principles, as much as $20 \mathrm{mg}$ of manganese can be handled. It is therefore possible to use $1 \mathrm{~g}$ samples in practically all cases. The results obtained by this procedure are much better than those obtained on smaller samples by the ordinary persulphate method and are practically of the same order of accuracy as obtained by the standard and much more elaborate bismuthate method.

\section{CONTENTS}

Page

I. Introduction

573

II. Historical

574

III. Experimental

574

IV. Recommended procedure

577

\section{INTRODUCTION}

In the persulphate-arsenite method for the determination of manganese in iron and steel manganese is converted to permanganic acid by oxidation with ammonium persulphate in a dilute nitric acid solution containing a small amount of a dissolved silver salt. The permanganic acid is titrated with a standard solution of sodium arsenite. Determinations can be quickly made and, hence, the method is extensively used in steelworks laboratories. Most of the procedures used are essentially the same as the one described in the American Society for Testing Materials Standards. ${ }^{1}$ However, the method is subject to certain limitations: That is (1) the use of a small sample and (2) difficulty in always obtaining proper oxidation of the manganese. The work discussed herein was done for the purpose of securing data whereby the method might be improved.

\footnotetext{
1 A. S. T. M. Standards, 1927, Pt, I, p, 287 ,
} 


\section{HISTORICAL}

The oxidation of $\mathrm{Mn}^{\mathrm{II}}$ to $\mathrm{Mn}^{\mathrm{VII}}$ by ammonium persulphate with silver nitrate as a catalyst was first described by Marshall. ${ }^{2}$ Walters ${ }^{3}$ applied the method to the oxidation of manganese in steels and estimated the permanganic acid by a colorimetric method. E. Proctor Smith ${ }^{4}$ oxidized manganese in the same way and titrated the permanganic acid with a solution of sodium arsenite. A number of modifications of Smith's procedure have been published from time to time. In applying the persulphate-arsenite method to manganese in tungsten steels Nicolardot and Levi ${ }^{5}$ used a mixture of sulphuric, nitric, and phosphoric acids. The phosphoric acid was used to keep the tungsten in solution. Ward ${ }^{6}$ likewise treated tungsten steels with dilute sulphuric acid, then added nitric and phosphoric acids, and boiled until tungsten carbides dissolved. Mathevet ${ }^{7}$ also published a procedure in which a mixture of the three acids was used to dissolve a $1 \mathrm{~g}$ sample of steel. He stated that the presence of phosphoric acid during oxidation prevents the precipitation of manganese dioxide which always occurs in nitric acid solution when the amount of manganese exceeds 8 to $10 \mathrm{mg}$. Willard and Greathouse ${ }^{8}$ found that phosphoric acid is efficient in preventing the precipitation of manganese compounds during oxidation with periodate. Eder, ${ }^{9}$ Bertiaux, ${ }^{10}$ Travers, ${ }^{11}$ and Mukerjee ${ }^{12}$ used phosphoric acid in connection with the determination of manganese by the persulphate method. Travers, by the aid of metaphosphoric acid $\left(\mathrm{HPO}_{3}\right)$, quantitatively oxidized $0.50 \mathrm{~g}$ of $\mathrm{Mn}^{\mathrm{II}}$ to $\mathrm{Mn}^{\mathrm{VII}}$, but he used hydrogen peroxide to titrate the permanganate because, as indicated later, the arsenite end point is not satisfactory for amounts of manganese above $20 \mathrm{mg}$. Kelley et al. ${ }^{13}$ and Hall and Carlson ${ }^{14}$ employed the potentiometric method for the titration of permanganic acid. The former used mercurous nitrate and the latter sodium arsenite.

\section{EXPERIMENTAL}

The ordinary persulphate-arsenite method is not suited to the determination of more than 2 to $3 \mathrm{mg}$ of manganese. Furthermore, the amounts of reacting constituents can not be modified to take care of more than approximately $7 \mathrm{mg}$ of manganese. As previously pointed out, larger amounts of manganese can be handled when phospharic acid is employed. All of the experiments were, therefore, made with acid mixtures containing phosphoric acid.

${ }^{2}$ Chem. News, 83, p. 76; 1901.

3 Chem. News, 84, p. 239; 1901.

${ }_{4}$ Chem. News, 90, p. 237; 1904.

$\checkmark$ Rev. Métal, 16, p. 201; 1919.

6 Chem. and Met., Eng. 23, p. 28; 1920.

7 Ann. anal. chlm. appl., 5, pp. 99-108; 1923.

8 J, Am. Chem. Soc., 39, p. 2366; 1917.
${ }^{9}$ Chem. Zeit., 46, No. 144, p. 1085; 1922.

10 Bull. soc. chim. de France, 35, p. 1335; 1925.

11 Ann. chim., 6, p. 56; 1926.

12 Analyst, 52, p. 689; 1927.

13 J. Ind. Eng. Chem., 10, p. 22; 1918.

14 J. Am. Chem. Soc., 45, p. 1615; 1923. 
Bertiaux has shown that with phosphoric acid present $100 \mathrm{mg}$ of manganese per 200 to $225 \mathrm{ml}$ can be oxidized to permanganic acid by persulphate and a silver nitrate catalyst without any separation of manganese dioxide. He titrated the permanganic acid with ferrous sulphate or oxalic acid because the theoretical factor which he used for the arsenite solution did not hold for manganese in excess of $4 \mathrm{mg}$. These first two reducing agents, however, react with chromates and can not be used for general steelwork. It is therefore more desirable to use arsenite even though the amount of manganese must be limited. The end point with arsenite can be observed fairly well with $20 \mathrm{mg}$ of manganese, but it is best not to use more than $15 \mathrm{mg}$ for accurate analyses.

The observations incident to the experimental work on the acidity, concentration of reagents, etc., presented in a summarized form, are as follows:

In solutions containing $10 \mathrm{mg}$ of manganese per $100 \mathrm{ml}$ manganese dioxide is precipitated during oxidation if $0.01 \mathrm{~g}$ of silver is used. Oxidation is quantitative with 0.02 to $0.03 \mathrm{~g}$ of silver. The use of $0.05 \mathrm{~g}$ of silver ( $0.079 \mathrm{~g}$ of silver nitrate) insures an ample margin of safety.

With this amount of silver nitrate and $1.5 \mathrm{~g}$ of ammonium persulphate, some manganese dioxide is precipitated. With $2.5 \mathrm{~g}$ of persulphate, oxidation of the manganese is satisfactory.

One milliliter of phosphoric acid gives satisfactory conditions for the oxidation of $12 \mathrm{mg}$ of manganese in the presence of $1 \mathrm{~g}$ of iron, but it is necessary to use 3 to $4 \mathrm{ml}$ of phosphoric acid in order to avoid the color interference of ferric iron.

The amounts of nitric and sulphuric acids can be varied somewhat without affecting the results, provided the arsenite is standardized by titrating in solutions containing the same concentration of acids.

The time required to quantitatively oxidize the manganese to permanganic acid depends upon the temperature, other conditions being constant. It was observed that oxidation is complete if the persulphate is added to a cool solution which is rapidly brought to boiling temperature and boiled about a half minute.

Addition of sodium chloride, after the manganese has been oxidized, to remove the silver ion is recommended in a number of methods, for it prevents reoxidation of manganese by the residual persulphate during the titration with arsenite in the hot solutions that are used by some analysts. The end point of the titration is affected by the amount of chloride used, ${ }^{15}$ and for accurate work the amounts of sodium chloride and silver nitrate must be held within very narrow limits. If the titration is carried out at temperatures below $25^{\circ} \mathrm{C}$., 
sodium chloride is not needed, for no appreciable reoxidation by persulphate takes place in the time necessary for titration.

As a result of numerous tests it was noted that the end point taken when permanganic acid is titrated with sodium arsenite is slightly influenced by the silver salt, the persulphate, and the degree of acidity. ${ }^{16}$ An acid solution of permanganic acid when titrated with sodium arsenite does not react in accordance with the ratio $\mathrm{Mn}_{2} \mathrm{O}_{7}$ : $2 \mathrm{MnO}$, but more nearly as indicated by the ratio $\mathrm{Mn}_{2} \mathrm{O}_{7}: \mathrm{Mn}_{3} \mathrm{O}_{5}$. In the presence of the silver ion the reduction of permanganate by arsenite is significantly less than when silver is absent. It was observed, however, that solutions of permanganic acid in which the concentrations of silver, acid, and persulphate were kept constant could be titrated with arsenite to reproducible end points. It seems possible, therefore, that the arsenite solution might be standardized with a permanganate solution, the titer of which had been determined by means of a primary standard such as sodium oxalate. It is general practice in standardizing the arsenite solutions to use a steel in which the manganese has been determined by some other method. This, of course, introduces into the persulphate-arsenite method those errors incident to the evaluation of the manganese in the standard steel.

The most desirable conditions for the standardization of the arsenite solution were established by the following experiments. In the first series $20 \mathrm{ml}$ of $0.03 \mathrm{~N}$ potassium permanganate was added to the solution of the reagents, prepared according to the recommended method (described later), and titrated directly with arsenite. In a second series the same amount of potassium permanganate was reduced with sulphurous acid, then oxidized according to the recommended method and titrated with arsenite. The third series was the same as the first except that $1 \mathrm{~g}$ of electrolytic iron (manganese 0.002 per cent) was present in the acid solution. The results are shown in Table 1.

TABLE 1.-Results obtained by standardization of the arsenite solution with standard potassium permanganate

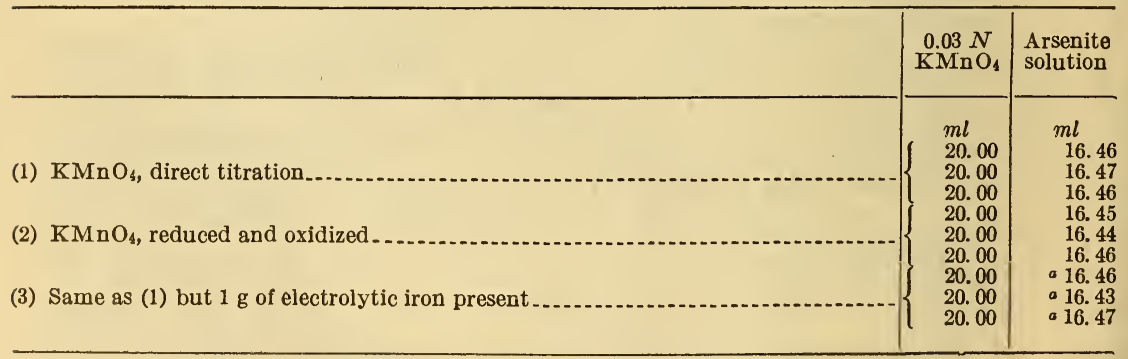

a $0.05 \mathrm{ml}$ has been subtracted for the manganese in the electrolytic iron.

${ }_{10}$ This has also been noted by Geloso, who states in Compt. rend., 171, p. 1145; 1920, that manganese and silver salts affect the end point if potassium permanganate is titrated with arsenite in sulphuric acid solution. 
The data in Table 1 show that it is optional whether the permanganate solution is titrated directly or reduced and oxidized. Furthermore, $1 \mathrm{~g}$ of iron introduces no significant differences.

On the basis of the preceding experiments the following procedure was then adopted for the determination of manganese in steel and iron. In this method as much as $20 \mathrm{mg}$ of manganese can be used, and it is therefore possible to use $1 \mathrm{~g}$ samples in practically all cases. Some time after the method had been put in daily use at the Bureau of Standards it was learned that W. D. Brown, ${ }^{17}$ of the Carnegie Steel Co., Duquesne, Pa., also uses a persulphate-arsenite method in which phosphoric acid is employed.

The results obtained by the recommended procedure are much better than those obtained heretofore on smaller samples by the ordinary persulphate method and are practically of the same order of accuracy as those obtained by the bismuthate method, which requires more time.

\section{RECOMMENDED PROCEDURE}

\section{SOLUTIONS REQUIRED}

Acid mixture:

Distilled water....... 525

Sulphuric acid (sp. gr. 1.84)

Phosphoric acid (85 per cent)

Nitric acid (sp. gr. 1.42)

Add the sulphuric acid to the water, mix and cool, add the nitric and phosphoric acids and again mix.

Silver nitrate $(0.8$ per cent):

Silver nitrate.

Distilled water Ammonium persulphate (25 per cent):

Ammonium persulphate.

Distilled water g-

This solution deteriorates and should not be kept more than a few days.

Standard sodium arsenite solution approximately $0.03 \mathrm{~N}$ ).-To $6 \mathrm{~g}$ of C. P. arsenic trioxide in a $600 \mathrm{ml}$ beaker add $250 \mathrm{ml}$ of water and 15 $\mathrm{g}$ of sodium hydroxide and stir until solution is complete. Saturate with carbon dioxide and dilute to 5 liters. Standardize as follows: Transfer $30 \mathrm{ml}$ of the acid mixture to a $500 \mathrm{ml}$ Erlenmeyer flask, add $100 \mathrm{ml}$ of water, $10 \mathrm{ml}$ of persulphate solution, $10 \mathrm{ml}$ of silver nitrate solution, and boil for a minute to remove any nitrous fumes. Cool to room temperature, add $75 \mathrm{ml}$ of water, exactly $20 \mathrm{ml}$ of a standard $0.03 \mathrm{~N}$ potassium permanganate solution, and titrate with the sodium

17 Private communication.

${ }_{18}$ Or necessary equivalent if strength is less than 95 per cent. 
arsenite solution. The end point should be taken when the solution assumes a yellow green color which is not changed by the further addition of arsenite.

\section{METHOD}

To $1.000 \mathrm{~g}$ of the steel or iron (note 1 ) in a $500-\mathrm{ml}$ Erlenmeyer flask add $30 \mathrm{ml}$ of the acid mixture. Heat until solution is complete and boil until oxides of nitrogen have been expelled. Add $100 \mathrm{ml}$ of cold water, $10 \mathrm{ml}$ of the silver nitrate solution, and $10 \mathrm{ml}$ of ammonium persulphate solution. Heat to boiling and boil briskly for one-half minute. Cool to $25^{\circ} \mathrm{C}$. or lower, add $75 \mathrm{ml}$ of cold water, and titrate with standard arsenite to a clear yellow end point ${ }^{19}$ which does not change upon the addition of more arsenite.

\section{NOTES}

1. For cast irons dissolve as directed, filter off the graphite through a rapid paper, and wash with water. Dilute the filtrate, if necessary, to $125 \mathrm{ml}$ and proceed as above.

2. If the operations are performed as directed, it is not necessary to make a preliminary oxidation of the solution.

3. Large amounts of chromium interfere because the yellow color of the chromate masks the pink color of the permanganic acid as the end point is approached. However, no particular difficulty was experienced when the amount of chromium did not exceed $15 \mathrm{mg}$.

4. Chrome-tungsten steels do not dissolve readily in the acid mixture. For such steels add $50 \mathrm{ml}$ of dilute sulphuric acid $(1: 9)$ and $3 \mathrm{ml}$ of phosphoric acid ( 85 per cent) to a $0.5 \mathrm{~g}$ sample and heat until action ceases. Add $40 \mathrm{ml}$ of water, $10 \mathrm{ml}$ of nitric acid (sp. gr. 1.20), and boil until tungsten carbides are all dissolved. Dilute, oxidize, etc., as for plain steel.

5. It is not desirable to incorporate the silver nitrate with the acid mixture because it tends to retard solution of some types of steels, more particularly certain nickel steels.

\section{RESULTS OBTAINED}

The performance of the method is illustrated by the results obtained in analyses of Bureau of Standards standard steels and in analyses of synthetic mixtures containing $1 \mathrm{~g}$ of electrolytic iron (manganese 0.002 per cent) and varying amounts of reduced $0.02 \mathrm{~N}$ potassium permanganate. These are shown in Tables 2 and 3.

${ }_{19}$ The color of the solution at the end point does not possess the green tint obtained in the absence of iron. However, the difference in shade is slight, and with a little practice the same end point can be obtained as in the absence of iron. 
TABLE 2.-Results obtained by applying the recommended method to the analysis of synthetic solutions prepared by dissolving $1 \mathrm{~g}$ of electrolytic iron and adding reduced $0.02 \mathrm{~N} \mathrm{KMnO}_{4}$ solution

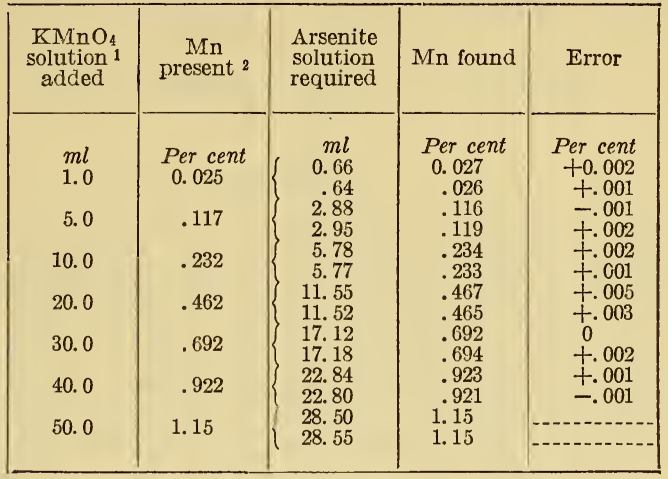

$11 \mathrm{ml}$ of $\mathrm{KMnO}_{4}=0.000230 \mathrm{~g}$ of $\mathrm{Mn}$.

2 Nanganese in the $\mathrm{KMnO}_{4}$ plus that in the iron.

TABLE 3.-Results obtained by applying the method to the analysis of Bureau of Stundards standard steels

\begin{tabular}{|c|c|c|c|c|}
\hline $\begin{array}{l}\text { Stand- } \\
\text { ard No. }\end{array}$ & $\begin{array}{l}\text { Certifi- } \\
\text { cate value }\end{array}$ & $\begin{array}{l}\text { Mn } \\
\text { found }\end{array}$ & $\begin{array}{l}\text { Differ- } \\
\text { ence }\end{array}$ & Type of steel \\
\hline $35 \mathrm{a} \ldots \ldots$ & $\begin{array}{r}\text { Per cent } \\
0.345\end{array}$ & $\left\{\begin{array}{r}\text { Per cent } \\
0.342 \\
.345\end{array}\right.$ & $\begin{array}{c}\text { Per cent } \\
-0.003 \\
0\end{array}$ & A. O. H. 1 per cent carbon. \\
\hline $16 b_{-. .}$ & .381 & $\left\{\begin{array}{l}.380 \\
.380\end{array}\right.$ & $\begin{array}{l}-.001 \\
-.001\end{array}$ & B. O. H. 1 per cen $\iota$ carbon. \\
\hline $11 c_{--}$ & .435 & $\begin{array}{r}.436 \\
.434\end{array}$ & $\begin{array}{r}+.001 \\
-.001\end{array}$ & B. O. H. 0.2 per cent carbon. \\
\hline $8 \mathrm{~d}_{---}$ & .482 & .482 & $\begin{array}{l}0 \\
+.003\end{array}$ & Bessemer 0.1 per cent carbon. \\
\hline $23 a_{-}$ & .634 & .638 & $\begin{array}{l}+.004 \\
+.004\end{array}$ & Bessemer 0.8 per cent carbon. \\
\hline $10 \mathrm{~d}$ & .915 & .915 & $\begin{array}{l}0 \\
+.001\end{array}$ & Bessemer 0.4 per cent carbon. \\
\hline $33 b_{--.}$ & .700 & .703 & $\begin{array}{l}+.003 \\
+.006\end{array}$ & Nickel steel $(3.5$ per cent $\mathrm{Ni})$ \\
\hline $72 \ldots$ & .651 & .646 & $\begin{array}{l}-.005 \\
+.001\end{array}$ & $\begin{array}{l}\text { Chrome-molybdenum steel ( } 0.91 \text { per cent chromium, } 0.15 \text { per } \\
\text { cent molybdenum). }\end{array}$ \\
\hline $30 \mathrm{~b}$ & .499 & .493 & $\begin{array}{l}-.006 \\
-.003\end{array}$ & $\begin{array}{l}\text { Chrome-vanadium steel ( } 1.00 \text { per cent chromium, } 0.21 \text { per cent } \\
\text { vanadium). }\end{array}$ \\
\hline
\end{tabular}

Grateful acknowledgment is made to Dr. G. E. F. Lundell for assistance in preparing this article.

Washington, June 15, 1929. 